\title{
STUDY OF RETINAL NERVE FIBER LAYER THICKNESS BY OPTICAL COHERENCE TOMOGRAPHY IN PRIMARY OPEN ANGLE GLAUCOMA, GLAUCOMA SUSPECT AND NORMAL NEPALESE POPULATION
}

\author{
Godar ST, Kaini KR
}

Department of Ophthalmology, Manipal College of Medical Sciences, Pokhara, Nepal

\begin{abstract}
The measurement of retinal nerve fiber layer thickness can help significantly in the early diagnosis of glaucoma and monitoring of its progression. The objective of this study was to compare the retinal nerve fiber layer (RNFL) thickness by optical coherence tomography in primary open angle glaucoma, glaucoma suspects and normal Nepalese population. This was a hospital based crosssectional study conducted in the Ophthalmology Out Patient Department of Manipal Teaching Hospital, Pokhara. Total 100 numbers of subjects (40 primary open angle glaucoma, 30 glaucoma suspects and 30 normal people) were evaluated. Complete ophthalmological examinations including tonometry, gonioscopy, optical coherence tomography, perimetry were performed. Statistical analysis was carried out using Epi-info 7. The result showed that the average retinal nerve fiber layer (RNFL) thickness was $70.22 \pm 12.07 \mu \mathrm{m}$ in right eye and $69.42 \pm 11.53 \mu \mathrm{m}$ in left eye in primary open angle glaucoma (POAG), $88.87 \pm 10.39 \mu \mathrm{m}$ in right eye and $88.73 \pm 9.59 \mu \mathrm{m}$ in left eye in glaucoma suspects (GS) and $94.40 \pm 9.21 \mu \mathrm{m}$ in right eye and $94.73 \pm 6.76 \mu \mathrm{m}$ in left eye in normal group respectively. The mean RNFL thickness was statistically significant in all three comparison groups except in nasal quadrant. The mean RNFL thickness was statistically significant in two comparison groups except in GS-Normal (nasal and temporal quadrant), GSPOAG (left nasal quadrant) and Normal-POAG (left nasal quadrant). The study concluded that the RNFL thickness is lower in POAG as compared to glaucoma suspects and normal group in the Nepalese population.
\end{abstract}

\section{KEYWORDS}

Glaucoma suspect, optical coherence tomography, primary open angle glaucoma, retinal nerve fiber

\section{CORRESPONDING AUTHOR}

Dr. Srijana Thapa Godar,

Assistant Professor

Department of Ophthalmology,

Manipal College of Medical Sciences, Pokhara, Nepal

Email: drsrijanathapa@gmail.com

Orchid No: https://orcid.org/0000-0002-0699-2464

DOI: https://doi.org/10.3126/nmcj.v22i3.32635 


\section{INTRODUCTION}

Glaucoma is defined by a characteristic optic neuropathy that is consistent with remodeling of the connective tissue elements of the optic nerve head and with loss of neural tissue associated with the eventual development of the distinctive patterns of visual dysfunction. ${ }^{1}$ Glaucoma affects more than 70 million worldwide with approximately $10 \%$ being bilaterally blind. There are 60.5 million people affected by primary open angle glaucoma which is expected to rise to 79.6 million by $2020 .^{2}$ The first nationwide epidemiological survey done in Nepal reported $0.84 \%$ prevalence of blindness in Nepal and found $3.2 \%$ cases were blind due to glaucoma. ${ }^{3}$

Glaucoma is one of the main causes of irreversible legal blindness worldwide and the second cause of loss of vision in patient over 40 years of age in the developed countries, ${ }^{4}$ with an important impact on quality of life. ${ }^{5-7}$ Early diagnosis and treatment of glaucoma has been shown to reduce the rate of disease progression and improve patient's quality of life. ${ }^{8}$

Optical coherence tomography (OCT) developed in 1991, is an imaging technology that performs high- resolution, cross- sectional imaging of the optic nerve head, retinal nerve fiber layer and macula. ${ }^{9}$ Retinal nerve fiber loss precedes measurable optic nerve head and visual field damage and is observed in $60 \%$ of eyes approximately six years before any detectable visual field defect in glaucoma. ${ }^{10}$ OCT is used for the detection of early structural glaucomatous nerve alternations that precede optic disc and visual field damage. ${ }^{11}$ Retinal nerve fiber layer analysis is the most commonly used scanning protocol for glaucoma diagnosis. ${ }^{12-14}$

The objective of the study was to compare the retinal nerve fiber layer thickness by optical coherence tomography in primary open angle glaucoma (POAG), glaucoma suspects (GS) and the normal Nepalese population.

\section{MATERIALS AND METHODS}

This was a hospital based cross-sectional study conducted in OPD of the Department of Ophthalmology, Manipal Teaching Hospital, Pokhara, Nepal for one year (from April 2019 to March 2020). Ethical approval was taken from the Institutional Review Committee of the Manipal College of Medical Sciences, Pokhara before the start of the study. The total of 100 patients aged 40 years and older were enrolled for the study ( 40 patients of POAG, 30 patients of GS and 30 normal samples) after taking informed consent. The patients with opacity in cornea, lens or vitreous, refractive error more than +/- 5.0 Dsph or 2.0 Dcyl or those with optic nerve pathology other than glaucoma or any other neurological damage were excluded from the study. Patients with hypertensive and diabetic retinopathy or history of prior intraocular surgery or trauma were also excluded from the study.

Relevant history and detailed ocular examination was performed including refraction, anterior segment evaluation by slit lamp and fundus evaluation after full dilatation using +90D Volk lens and +20D lens. Intra ocular pressure was measured with applanation tonometer, gonioscopy with Volk Three - Mirror Gonio lens, visual field examination with Humphrey SITA Standard, 24-2 Static threshold perimeter (Model no. Humphrey field Analyser II - i series Ziess company), central corneal thickness with optical coherence tomography and optic disc cube 200x200 and retinal nerve fiber thickness measurement by using Carl Zeiss Spectral Domain OCT V3.

Primary open angle glaucoma (POAG) is defined by following three criteria:

1. An intraocular pressure (IOP) consistently above $21 \mathrm{mmHg}$ in at least one eye

2. An open, normal appearing anterior chamber angle with no apparent ocular or systemic abnormalities that might account for the elevated IOP

3. Optic nerve head damaged with typical glaucomatous visual field changes.

Criteria for glaucoma suspect: Subjects with raised intraocular pressure or glaucomatous optic disc changes or visual field abnormalities in isolation.

Criteria for normal: Subjects with no history of ocular disease. Intraocular pressure should be less than or equal to $21 \mathrm{mmHg}$, normal optic disc appearance and normal perimetry.

The statistical tests used were mean, chi-square and analysis of variance (ANOVA). Data entry and analysis was done in Epi-info version 7. The p-value less than 0.05 was considered significant in this study.

\section{RESULTS}

A total of 100 patients were included in the study. The mean age \pm standard deviation was $62.03 \pm 13.39$ years in POAG group, $56.03 \pm 12.61$ years in GS group and $50.57 \pm 9.01$ years in normal group. The mean age difference 
between the three groups was statistically significant. There was statistical significance in gender of the participants, but not in their place of residence (Table1).
Table 2 shows the comparison of the mean retinal nerve fiber layer thickness in POAG, GS and normal groups. The mean was statistically significant in average RNFL as well as in

\begin{tabular}{|c|c|c|c|c|c|c|}
\hline \multicolumn{2}{|l|}{ Variables } & POAG $(n=40)$ & GS $(n=30)$ & Normal $(n=30)$ & Chi-square & p-value \\
\hline \multicolumn{2}{|c|}{$\begin{array}{l}\text { Mean Age } \pm S D \\
\text { (in years) }\end{array}$} & $\begin{array}{c}62.03 \\
( \pm 13.39)\end{array}$ & $\begin{array}{c}56.03 \\
( \pm 12.61)\end{array}$ & $\begin{array}{c}50.57 \\
( \pm 9.01)\end{array}$ & & 0.0007 \\
\hline \multirow{2}{*}{ Gender } & Female & 18 & 24 & 23 & \multirow{2}{*}{11.79} & \multirow{2}{*}{0.0027} \\
\hline & Male & 22 & 6 & 7 & & \\
\hline \multirow{2}{*}{ Residence } & Urban & 25 & 22 & 21 & \multirow{2}{*}{1.0034} & \multirow{2}{*}{0.6055} \\
\hline & Rural & 15 & 8 & 9 & & \\
\hline
\end{tabular}

\section{Table 2: Comparison of mean retinal nerve fiber layer thickness between the study groups.}

\begin{tabular}{|lccccc|}
\multicolumn{2}{l}{ RNFL thickness (in $\boldsymbol{\mu m}$ ) } & POAG & GS & Normal & p-value \\
Average & Right eye & $70.22( \pm 12.07)$ & $88.87( \pm 10.39)$ & $94.40( \pm 9.21)$ & 0.0000 \\
& Left eye & $69.42( \pm 11.53)$ & $88.73( \pm 9.59)$ & $94.73( \pm 6.76)$ & 0.0000 \\
Superior quadrant & Right eye & $91.05( \pm 20.88)$ & $110.20( \pm 15.11)$ & $121.10( \pm 14.80)$ & 0.0000 \\
& Left eye & $89.32( \pm 23.42)$ & $114.26( \pm 16.13)$ & $124.90( \pm 12.64)$ & 0.0000 \\
Nasal quadrant & Right eye & $61.87( \pm 7.47)$ & $67.73( \pm 10.70)$ & $67.56( \pm 11.63)$ & 0.0192 \\
& Left eye & $60.17( \pm 8.50)$ & $65.00( \pm 10.81)$ & $64.06( \pm 11.06)$ & 0.1026 \\
Inferior quadrant & Right eye & $76.12( \pm 31.58)$ & $117.06( \pm 16.38)$ & $128.30( \pm 17.50)$ & 0.0000 \\
& Left eye & $76.50( \pm 28.07)$ & $114.16( \pm 13.58)$ & $126.80( \pm 15.13)$ & 0.0000 \\
Temporal quadrant & Right eye & $50.52( \pm 11.58)$ & $60.30( \pm 8.87)$ & $62.16( \pm 5.88)$ & 0.0000 \\
& Left eye & $52.45( \pm 9.47)$ & $61.33( \pm 13.11)$ & $61.00( \pm 6.96)$ & 0.0003 \\
\hline
\end{tabular}

Table 3: Comparison of mean retinal nerve fiber layer thickness between two study groups.

\section{RNFL thickness (in $\mu \mathrm{m}$ )}

Average

Superior quadrant

Nasal quadrant

Inferior quadrant

Temporal quadrant
GS-POAG (p-value)

0.0000

0.0000

0.0000

0.0000

0.0192

0.1026

0.0000

0.0000

0.0000

0.0003

\section{GS-Normal} (p-value)

0.0332

0.0332

0.0069

0.0065

0.0062

0.9541

0.7422

0.0129

0.0012

0.3411

0.9026
Normal-POAG (p-value)

0.0000

0.0000

0.0000

0.0000

0.0153

0.1005

0.0000

0.0000

0.0000

0.0001 
superior, inferior and temporal quadrant in both right and left eyes, except in nasal quadrant.

Table 3 shows the comparison of the mean retinal nerve fiber layer thickness between the two groups. The mean RNFL thickness was statistically significant between two comparison groups except in GS-Normal (nasal and temporal quadrant), GS-POAG (left nasal quadrant) and Normal-POAG (left nasal quadrant).

\section{DISCUSSION}

Glaucoma is the second leading cause of blindness worldwide. The main goal of glaucoma management is to diagnose when patients are asymptomatic. Visual field testing is important in the diagnosis and monitoring of glaucoma, however, standard perimetry alone cannot detect visual field defects until $20 \%-40 \%$ of ganglion cells have been lost. ${ }^{15,16}$ Retinal nerve fiber layer defects have been detected earlier than visual field defects with Optical coherence tomography. Measuring RNFL thickness by OCT helps in quantitative assessment of glaucomatous structural loss. ${ }^{17}$

In our study the mean age $( \pm S D)$ was 62.03 years ( \pm 13.39 years) in POAG group, 56.03years $( \pm 12.61$ years) in GS group and 50.57 years ( \pm 9.01 years) in normal group and was statistically significant. A study in India noted that the mean age \pm SD was $57.4 \pm 10.4$ years in glaucomatous eyes, $51.6 \pm 10.5$ years in eyes with ocular hypertension and $51.1 \pm 12.9$ years in normal eyes and was significantly higher in patients with glaucoma compared with normal patients and patients with ocular hypertension. ${ }^{18}$ Our results were similar to a study in Greece where mean age for normal group was $58.03 \pm 15.62$ years and for glaucomatous $62.57 \pm 14.5$ years. ${ }^{19} \mathrm{~A}$ study in Nepal, however, observed no statistically significant difference in age. ${ }^{20}$

There was significant difference regarding gender between the three groups in this study. This is different from the studies done in India, ${ }^{18}$ $\mathrm{Nepal}^{20}$ and USA ${ }^{21}$ which showed no statistically significant difference.

There was significant thinning of RNFL in POAG compared with GS and normal group. In the RNFL thickness measurement in different quadrants, we observed that it was thickest in the inferior followed by superior, nasal and temporal quadrant. Similar results was seen in a study conducted at Nepal, where the mean RNFL thickness was $109.8 \pm 8.32 \mu \mathrm{m}$ in normal eyes,
$102.0 \pm 9.37 \mu \mathrm{m}$ in GS and $64.30 \pm 14.45 \mu \mathrm{m}$ in eyes with POAG. ${ }^{20}$ Similar study in China observed the mean RNFL thickness was significantly higher in the inferior sector $(131.4 \pm 20.6 \mu \mathrm{m})$ followed by superior sector $(126.1 \pm 19.1 \mu \mathrm{m})$, temporal sector $(79.8 \pm 12.2 \mu \mathrm{m})$ and nasal sector $(75.1 \pm 12.6 \mu \mathrm{m}){ }^{22}$ The RNFL thickness distribution in normal eyes was such that the inferior quadrant was the thickest followed by superior, nasal and temporal quadrant. This follows the convection that is often referred to as ISNT rule in glaucoma. ${ }^{23}$ Mean RNFL thickness was statistically significantly less in glaucomatous eyes $(56.9 \pm 21.5 \mu \mathrm{m})$ than in eyes with ocular hypertension $(83.7 \pm 16.6 \mu \mathrm{m})$ and normal eyes $(90.9 \pm 14.2 \mu \mathrm{m})$ in a study from USA. RNFL thickness was greater in normal than in ocular hypertensive eyes but it wasn't statistically significant. ${ }^{21} \mathrm{~A}$ study by Mansoori et $a l^{18}$ noted that mean RNFL thickness was $112.5 \pm 6.5 \mu \mathrm{m}$ in normal eyes, $110.1 \pm 10.9 \mu \mathrm{m}$ in eyes with ocular hypertension and $93.4 \pm 16.9 \mu \mathrm{m}$ in glaucomatous eyes. Mean RNFL thickness showed a significant difference between glaucomatous eyes, normal eyes and eyes with ocular hypertension. Mean RNFL thickness between normal eyes with ocular hypertension wasn’t statistically significant.

Our study was different from the study done in Greece which noted superior quadrant RNFL was thickest $(136.7 \pm 18)$ followed by inferior (134.5 \pm 18.1$)$, nasal $(107.2 \pm 17.8)$ and temporal (79.5 \pm 15.3$).^{19}$

Anton et al $^{24}$ reported that mean RNFL thickness around the disc and superior and inferior RNFL thickness was significantly thinner in glaucomatous eyes than in eyes with ocular hypertension or normal eyes. They found no significant difference in RNFL parameters between eyes with ocular hypertension and normal eyes. Most studies using Stratus OCT have identified the average and inferior average RNFL thickness as the best discrimination between normal and glaucomatous eyes. ${ }^{25}$ Our study also found inferior quadrant RNFL thickness to be the best parameter to differentiate between normal and glaucoma.

In our study, the RNFL thickness difference was statistically significant in all the quadrants except nasal between the study groups. However, only the superior and inferior RNFL was thinned significantly between normal and GS eyes. It may be due to the fact that the superior and inferior poles of the optic nerve head are more vulnerable to glaucomatous damage. A significant difference in quadrantic RNFL thickness across all comparison groups except Normal vs GS in which nasal and temporal 
RNFL thickness did not differ significantly as reported from a study by Khanal et al. ${ }^{20}$ Guedes et $a l^{26}$ reported that mean RNFL was the only parameter in which a statistically significant difference was observed between the normal and GS groups.

In conclusion, this study showed that there was statistical significance in RNFL thickness in POAG group as compared to GS and normal groups. RNFL thickness measurement by OCT can be used as an early tool to differentiate between normal, glaucoma suspect and glaucomatous eyes. This could help in early diagnosis and proper management of glaucoma patients. It would also help in the follow up of these patients.

\section{ACKNOWLEDGEMENT}

The authors would like to thank all the participants of this study.

\section{REFERENCES}

1. Cantor LB, Rapuano CJ, McCannel CA. Introduction to Glaucoma: Terminology, Epidemiology, and Heredity. In Girkin CA, editor. American Academy of Ophthalmology Glaucoma (2019-2020). San Francisco: American Academy of Ophthalmolgy 2019: 18.

2. Quigley HA, Broman AT. The number of people with glaucoma worldwide in 2010 and 2020. Br J Ophthalmol 2006; 90: 262-7.

3. Brilliant LB, Pokhrel RP, Grasset NC, et al. Epidemiology of blindness in Nepal. Bulletin of the World Health Organization 1985; 63: 375-86.

4. Kobelt G, Jonsson B, Bergstrom A, et al. Costeffectiveness analysis in glaucoma: what drives utility? Results from the pilot study in Sweden. Acta Ophthalmol Scand 2006; 84: 363-71.

5. Skalicky S, Goldberg I. Depression and quality of life in patients with glaucoma: a cross-sectional analysis using the Geriatric Depression Scale-15, assessment of function related to vision and the Glaucoma quality of life-15. J Glaucoma 2008; 17: 546-51.

6. McKean-Cowdin R, Wang Y, Wu J, Azen SP, Varma R. Impact of visual field loss on health-related quality of life in glaucoma: The Los Angeles Latino Eye Study. Ophthalmology 2008; 115: 9418.

7. Goldberg I, Clement CI, Chiang TH, et al. Assessing quality of life in patients with glaucoma using the Glaucoma Quality of Life-15 (GQL-15) questionnaire. J Glaucoma 2009; 18: 6-12.

8. Quigley HA, Katz J, Derick RJ, Gilbert D, Sommer A. An evaluation of optic disc and nerve fiber layer examinations in monitoring progression of early glaucoma damage. Ophthalmology 1992; 99: 19-28.

9. Fujimoto JG, Pitris C, Boppart SA, Brezinski ME. Optical coherence tomography: an emerging technology for biomedical imaging and optical biopsy. Neoplasia 2000; 2: 9-25.

10. Subbiah S, Sankarnanarayanan S, Thomas PA, Nelson Jesudasan CA. Comparative evaluation of glaucoma in ocular hypertensives, glaucomatous and normal eyes. Indian J Ophthalmol 2007; 55: 283-7.
11. Lalezary M, Medeiros FA, Weinreb RN, et al. Baseline optical coherence tomography predicts the development of glaucomatous change in glaucoma suspects. Am J Ophthalmol 2006; 142: 576-82.

12. Bussel II, Wollstein G, Schuman JS. OCT for glaucoma diagnosis, screening and detection of glaucoma progression. Br J Ophthalmol 2014; 98 : ii15-9.

13. Sung KR, Kim JS, Wollstein G, et al. Imaging of the retinal nerve fiber layer with Spectral domain optical coherence tomography for glaucoma diagnosis. Br J Ophthalmol 2011; 95: 909-14.

14. Leung CK, Cheung CYL, Weinreb RN, et al. Evaluation of Retinal Nerve Fiber Layer progression in Glaucoma: A Study on Optical Coherence Tomography Guided Progression Analysis. Invest Ophthalmol Vis Sci 2010; 51: 21722.

15. Quigley HA, Dunkeiberger GR, green WR. Retinal ganglion cell atrophy correlated with automated perimetry in human eyes with glaucoma. Am J Ophthalmol 1989; 107: 453-64.

16. Kerrigan-Baumrind LA, Quigley HA, Pease ME, Kerrigan DF, Mitchell RS. Number of ganglion cells in glaucoma eyes compared with threshold visual field tests in the same person. Invest Ophthalmol Vis Sci 2000; 41: 741-8.

17. Sung KR, Kim JS, Wallstein G, et al. Imaging of the retinal nerve fiber layer with spectral domain optical coherence tomography for glaucoma diagnosis. Br J Ophthalmol 2011; 95: 909-14.

18. Mansoori T, Viswanath K, Balakrishna N. Quantification of retinal nerve fiber layer thickness in normal eyes, eyes with ocular hypertension, and glaucomatous eyes with SDOCT. Ophthalmic Surg Lasers Imaging 2010; 41: S50-7.

19. Kampougeris G, Spyropoulos D, Mitropoulou A, Zografou A and Kosmides P. Peripapillary retinal nerve fiber layer thickness measurement with SD-OCT in normal and glaucomatous eyes: distribution and correlation with age. Int'l J Ophthalmol 2013; 6: 662-5.

20. Khanal S, Thapa M, Racette Lyne, et al. Retinal nerve fiber layer thickness in glaucomatous 
Nepalese eyes and its relation with visual field sensitivity. J Optom 2014; 7: 217-24.

21. Hoh ST, Greenfield DS, Mistlberger A, Liebmann JM. Ishikawa H, Ritch R. Optical coherence tomography and scanning laser polarimetry in normal, ocular hypertensive and glaucomatous eyes. Am J Ophthalmol 2000; 129: 129-35.

22. Wang YX, Pan Z, Zhao L, You QS, Xu L, Jonas JB. Retinal nerve fiber layer thickness. The Beijing Eye Study 2011. PloS One 2013; 8: e66763.

23. Morgan JE, Bourtsoukli I, Rajkumar KN, et al. The accuracy of the inferior $>$ superior $>$ nasal>temporal neuroretinal rim area rule for diagnosing glaucomatous optic disc damage. Ophthalmology 2012; 119: 723-30.
24. Anton A, Montanes JM, Blazquez F, Alvarez A, Martin B, Molina B. Usefulness of optical coherence tomography parameters of the optic disc and the retinal nerve fiber layer to differentiate glaucomatous, ocular hypertensive, and normal eyes. J Glaucoma 2007; 16: 1-8.

25. Choi MG, Han M, Kim YI, Lee JH. Comparison of glaucomatous parameters in normal, ocular hypertensive and glaucomatous eyes using optical coherence tomography 3000. Korean J Ophthalmol 2005; 19: 40-6.

26. Guedes V, Schuman JS, Hertzmark E. Optical coherence tomography measurement of macular and nerve fiber layer thickness in normal and glaucomatous human eyes. Ophthalmology 2003; 110: 177-89. 